\title{
Bizarre Platelet Count
}

National Cancer Institute

\section{Source}

National Cancer Institute. Bizarre Platelet Count. NCI Thesaurus. Code C154733.

The determination of the amount of bizarre platelets present in a sample. 